\title{
CHALLENGES OF DISTANCE EDUCATION DURING THE SCHOOL LOCKDOWN: THE LITHUANIAN SCHOOL LEADERS' PERSPECTIVE
}

\author{
Lina Kaminskienè \\ Vytautas Magnus University, Lithuania \\ Ling Yi Chu \\ Vytautas Magnus University, Lithuania
}

\begin{abstract}
The COVID19 pandemic has caused massive disruption in education practices worldwide and Lithuania was no exception. This article investigates how this period of uncertainties has been perceived by Lithuanian schools during school lockdown. The study aimed to explore the challenges that Lithuanian schools faced and how distance education practices has been reconsidered during school lockdown. The research was based on a survey of 406 sampled school leaders of public education institutions in Lithuania conducted two months into the first nationwide lockdown in spring 2020. This paper aims to discuss the challenges of distance education from the perspective of school leaders, and to link the findings of the study to recent studies related to schools' responses to the pandemic situation. The survey responses indicated that schools initially focused on the organisation of staff training and technological preparation to start distance education during the first two weeks of lockdown. Their focus two months into the process shifted towards tackling challenges on students' responsiveness and assessment of students' achievements during distance education. Challenges are perceived as opportunities for reflection and growth, re-examine current institution strengths and weaknesses, and reconsolidate with the school communities in prioritising what the utter function in education is.
\end{abstract}

Keywords: school leaderships, education in lockdown, distance education.

\section{Introduction}

The nation-wide school lockdown due to COVID-19 complications was announced on March 16, 2020, in Lithuania. It was disruptive and unexpected, requiring swift switching onto distance education, a major restructuring of educational activities, and thorough reorganisation of internal management. Despite the governments' two-weeks extension of school holidays as a buffer time for schools to prepare and transition to distance education, challenges were still experienced by school community members and school leadership. The research was based on a survey of school leaders of public education institutions in Lithuania conducted after the lockdown in spring 2020. This paper aims to discuss 
Kaminskiene \& Chu, 2021. Challenges of Distance Education During the School Lockdown: the Lithuanian School Leaders' Perspective

key challenges of distance education from the perspective of school leaders and links the findings of the study with recent studies related to schools' responses to the pandemic situation.

\section{Literature Review}

The impact of Covid-19 is currently disrupting educational institutions globally, with more than 1.6 billion students having been removed from their regular classrooms in the spring of 2020. Teaching and learning have been interrupted in every country, and many refer to this as an educational crisis. As 'crisis' carries the meaning of 'confronting, intrusive and painful experiences' (Smith and Riley 2012), it also often implies upcoming "turning point" moments, not necessarily toward the positive or the negative. This concept of 'turning point' can be used to understand the contemporary discourses around Covid-19 to be highly polarised and places schooling in a new definitional dilemma. Practical voices call for a rapid return to 'normal' and re-engagement from where the schools left off. Optimistic educators make waves for the co-creation of a postpandemic 'new normal' with the potential to a re-modelled education globally. Nevertheless, while face-to-face schools still inevitably dominate both the idea and the function of schooling itself, global school lockdowns engine the incorporation of new tools to tackle previously unthinkable challenges. It has been suggested as an opportunity to revise conventional practices so that more longterm and permanent changes may be implemented in the post-crisis context, rather than looking for quick fixes to merely survive the pandemic turbulence (Zhao 2020).

During Covid-19, members of the school community rely on its leadership to provide certainty and redirect focus, nurturing enduring hope, building resilience, and ensuring flexible communication. It is important to balance reacting to immediate needs and proactively prepare for the future while achieving the best student learning outcomes. Kerrissey and Edmondson (2020) suggested four positive approaches during uncertainties: acting with urgency; communicating with transparency; taking responsibility and focusing on solving problems and engaging in constant updating. The openness of school leaders assimilates to how members of the school community react to crisis and disruptive times, while collectively maintaining higher organisation morale and motivation for teaching performance and learning outcomes. 


\section{Methodology}

The questionnaire was developed in Slovenia by researchers from the University of Ljubljana (Kalin et al. 2020) and modified in Lithuania by researchers from Vytautas Magnus University. Several variables were singlechoice nominal variables: gender, school type, school area (urban or rural), and the teaching approach used by most teachers in the school. There was one multiple choice question: How did your school organise distant education? There were a few quantitative questions: Years of work experience, Years of being a principal, Number of students.

There were four questions, which were multiple choice; however, the number of choices was fixed in advance: Which three activities engaged you most as a principal during the first two weeks of the school lockdown? (3 possible answers), Which four activities engage you most at this moment? (4 answers), How do you monitor teachers' work? (3 answers), Which aspects of distant education do you find most challenging? (3 answers). The last six questions were about collaboration, cooperation and communication of principals with the Ministry of Education, Science and Sports (and other similar institutions, like the National Education Agency), with principals from other schools, and with colleagues from the respondent's own school.

In this paper, we will focus only on the discussion on the research results related to distance education challenges in three perspectives: immediately after the lockdown, after two months in the lockdown and assessing challenges of distance education in a long-term perspective.

Researchers conducted the study in May 2020 on the management of educational institutions during pandemic challenges, in which 17 vocational school leaders and 388 general education school leaders were surveyed. Out of the 1127 schools at the beginning of the school year, the questionnaire received 406 useable responses. The distribution of participants by gender reflects a situation in the Lithuanian educational system, which is dominated by women. Average work experience was 30.8 years ranging from 3 to 47 years, and work experience as a school director was 14.9 years on average, from 0 to 38 years.

\section{Research Results}

The study participants agreed $(97,8 \%)$ that the organisation of distance education was among the three main activities during the first two quarantine weeks. Two-thirds of the surveyed principals $(64,2 \%)$ noted that they provided support to teachers during this period; around half of the principals $(48,8 \%)$ focused on helping students who were unable to use information technologies; 
about a third of participants (34,3\%) noted prioritising interaction with parents and caregivers.

The situation slightly changed after two months in the lockdown. Still, a significant part of the school leaders $(77,7 \%)$ indicated that the main challenge remained the implementation of distance education, 51.5\% - communication with pupils' parents or caregivers, $48.8 \%$ noted that the provision of support to teachers remained among key challenges, $42.4 \%$ stressed increased problems with noncommunicative and non-responsive pupils and 38.2\% - assessment of achievements and personal progress of students.

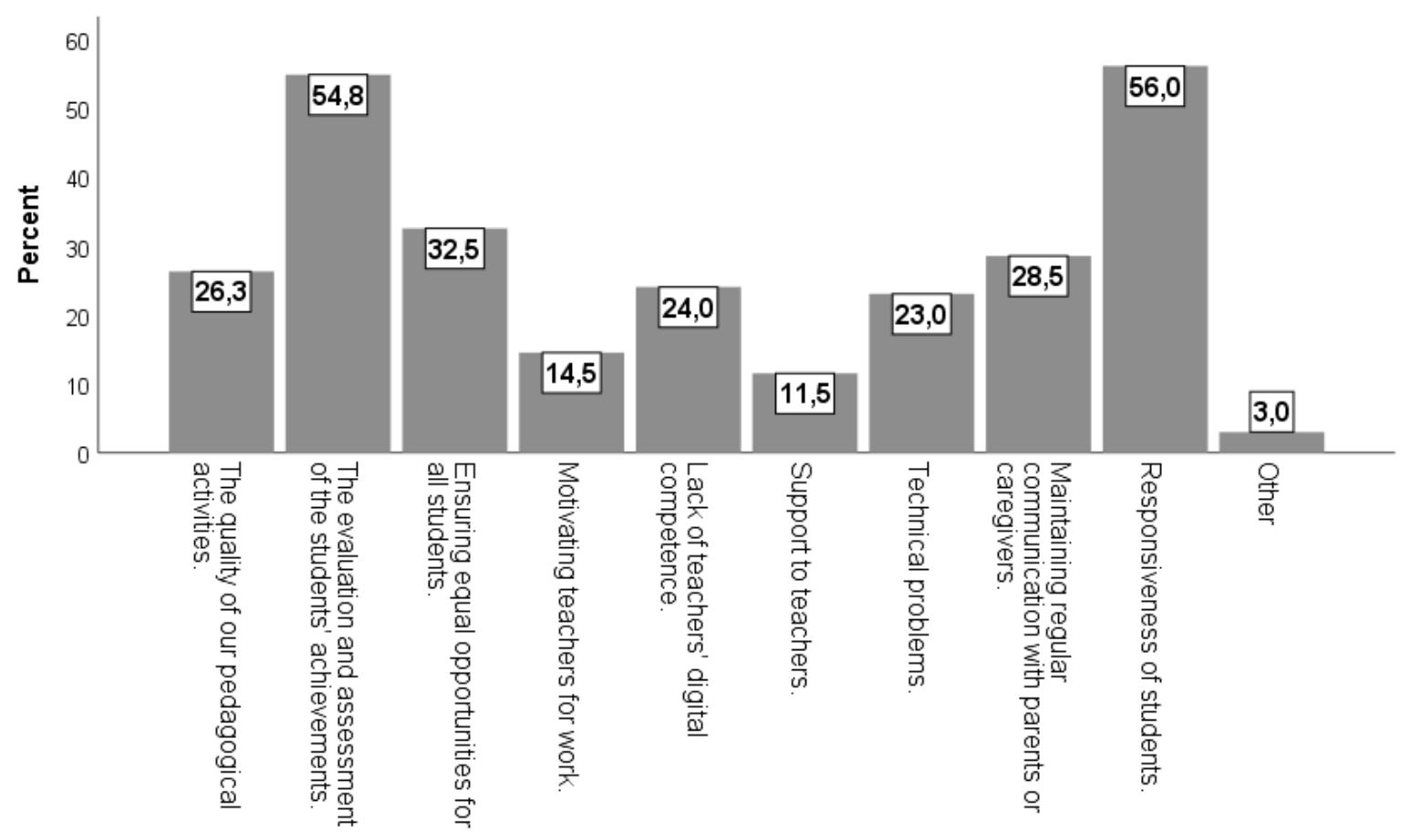

Figure 1 Challenges of Distance Education

Overall, evaluating the main challenges of distance education (Figure 1), school leaders remained systemic in their responses. Dealing with poor responsiveness of students (56\%), evaluation and assessment of students' achievements (54,8\%), ensuring equal opportunities for all students (32,5\%), maintaining regular communication with parents and caregivers (28,5\%) have been identified as the priority areas.

\section{Discussion}

The research revealed that Lithuanian schools addressed difficulties during the switch to distance education, similar to what Cabaj and Weaver (2016) referred to as a "collective impact" in approaching complex social circumstances. It is apparent that Lithuanian school members were empowered to rediscovering 
new solutions that best serve the collective priorities (D’Auria and De Smet 2020). However, despite successful team effort, among the biggest challenges of distance education, respondents most often mentioned assessing students' achievements and communication with students.

Challenges on assessing student achievements that Lithuanian school reported during school closure is also highlighted by UNICEF educators: "some of the main implications of the COVID pandemic for assessment systems and practices in general surrounds challenges for pupils to maintain achievement and develop new skills" (UNICEF, 2020, p.1). As distance learning relies heavily on autonomy, younger learners and leaners who were not previously given the opportunity to take ownership of their self-learning may find it difficult to cope. According to UNICEF's 2020 recommendation to educators, uncertainties regarding students' learning level shifts will occur upon school reopening and face to face instruction resumed, and assessment is the central pillar in the 'back to school' process. Assessment during school-closure should thus be conducted with the following considerations: 1. Monitor learning throughout the crisis. Assessment during school closure should be used as individual learning journeys that allow teachers to prioritise support to pupils who have fallen furthest behind due to special needs, lack of support at home, or lack of access to technology or appropriate learning environments. 2. Reduce expectations for what and how much children can learn during COVID crisis period. The nature, content and stakes of assessment should reflect the crisis conditions that teachers and students are undertaking the assessments with expectations of the outcomes tempered to reflect the learning domains. 3. Prioritise formative assessment. Pupils should not be expected to progress across the intended curriculum through self-learning methods with few teachers' interactions. Distance learning programmes should utilise formative assessment components to incorporate teachers' direct feedback (also a channel of direct communication and keeping contact) regarding learning content and student error patterns. Expectations for formative assessment need to be clearly communicated with clear protocols in place when children are identified as not learning or not accessing distance programmes. 4. Provide guidance for parents: Pupils' learning level shifts may reflect the level of isolation and stress endeavoured, and assessment results can be used to indicate where parenting education is most needed. As sudden home-schooling load shifts from normal schooling into their households, counselling for parents is key during school closure for the well-being, preservation of learning motivation and maintenance of safety- for at times of crisis. Parents may find their children going beyond their necessary involvement in the learning and assessment culture of schools. Nevertheless, it is worth further investigation to follow-up on these school leaders' initiatives to explore the school's assessment process to obtain better insight into the pupils' learning conditions. 
Kaminskiene \& Chu, 2021. Challenges of Distance Education During the School Lockdown: the Lithuanian School Leaders' Perspective

The second flagged challenge that Lithuanian schools pointed out was maintaining contact with pupils and maintaining pupils' engagement in the learning process. Verheijen (2020) suggests the following: Firstly, increase the interactivity of work by applying flipped-classroom tools which may extend pupils' attention spans (Tang et al., 2020). SecEd (2020) stated: "Evidence on distance learning highlights the importance of interactive learning, consolidating learning and supporting pupils to self-regulate their learning as effective strategies as part of a mixed diet of provision" (p. 1). Both creativity and application of a variety of technologies that foster conversation, collaboration and personalised experiences would see higher engagement across the board. The UNESCO Institute for Information Technologies in Education's 2020 initiative: 'COVID-19: Keep learning. Together we are on the move!' (Zhan, 2020) for instance, has constructed a global platform and collection of open-source education technologies (technical solutions, resources for distance learning, guidance, and training opportunities). Secondly, make better use of the peer-to-peer network. This gives pupils ownership to their learning, encourages interaction amongst peers, and increases understanding of tasks and expectations such as grading. Peer learning is also a much-needed approach for the potentially ongoing blended education, switching between online and offline. The interactive nature of group tasks and peer-to-peer feedback promotes online conversations and consolidates previous learning while having higher pupil engagement levels, particularly an increased probability of having highly engaged disadvantaged pupils" (Lucas et al., 2020). Peer-to-peer formats are also more flexible for blended learning, can be switched between online and offline, and is less disrupted by the location where learning is taking place. In problem-solving with peers' support, vital skills for learning how to learn are also being demonstrated as part of the tasks. In the long term, this leads to the third point: emphasis self-guided learning. It is crucial to shaping pupils' online schooling as their own learning journey by tacking pupils' perspectives into account. Where multiple and immediately feasible tactics are applied, seat time and student progress can be reconsidered to allow learners' progression at the best rate they can achieve. For instance, Best (2020) suggested eight online assessment strategies for distance schooling which may offer more effective ways of evaluating learning outcomes: peer assessment, independent projects, jigsaw projects, self-assessment, portfolios and learning journals (examples of variations include challenge journals, success journals, visual journals and question journals). Recent studies on this matter are worth considering in terms of probable solutions.

All the above hinder the application of effective online tools, and in turn, allow for more accurate differentiation between learning levels (Schueler, 2020), and free up teachers to focus more on struggling pupils. Hegarty (2020) pointed out that as remote teaching prevents teachers from being physically present to 
notice students struggling, teachers need to be given a chance (both time and space) to apply digital platforms that offer easy-to-access data on the immediate progress of each student. Where data indicate student lagging - in both engagement and progress - instead of applying the problematic tracking approach, teachers may consider strategies that allow themselves to work directly with students most in need. It will be interesting to know more about the school leader's approaches toward pupil engagement during distance education as a way to ensure that no one is left behind.

\section{Conclusions}

The research discloses that the disruption of the normal teaching process by Covid-19 requires schools' collective efforts and enabling teachers' autonomy and expertise to deal with the methodical and organisational challenges of distance education transition. Current faced by Lithuanian schools, as any other distance education contexts on the assessment of students' achievements and engagement of students are not new ones. However, it is hopeful to see that schools can take these challenges as opportunities for reflection and growth, re-examine current institution strengths and weaknesses, and reconsolidate with the school communities in prioritising what the utter function in education is. For when schooling 'resumes to normal', the face of education will never be the same again.

\section{References}

Best, J. (2020). Online Assessment Strategies for Distance Teachers and Learners. 3P Learning. Retrieved from: https://www.3plearning.com/blog/online-assessment-strategiesdistance-teachers-learners/

Cabaj, M. \& Weaver, L. (2016). Collective Impact 3.0: An Evolving Framework for Community Change. Tamarack Institute: Waterloo, Ontario. Retrieved from: https://www.collective impactforum.org/sites/default/files/Collective\%20Impact\%203.0.pdf

D’Auria, G. \& De Smet, A. (2020). Leadership In A Crisis: Responding to the Coronavirus Outbreak and Future Challenges. McKinsey. Retrieved from: https://www.mckinsey.com/business-functions/organization/our-insights/leadership-ina-crisis-responding-to-the-coronavirus-outbreak-and-future-challenges

Hegarty, C. (2020). Covid challenge: How to make blended learning engaging for students. SecEd. Retrieved from: www.sec-ed.co.uk. https://www.sec-ed.co.uk/best-practice/ Covid-challenge-how-to-make-blended-learning-engaging-for-students-remoteeducation-coronavirus-lockdown-1/

Kalin, J., Ermenc, K., Mažgon, J. (2020). Izzivi vodenja šole v času izrednih razmer. Sodobna pedagogika, Special issue.

Kerrissey, M. \& Edmondson, A. (2020). What good leadership looks like during this pandemic. Harvard Business Review. Retrieved from: https://hbr.org/2020/04/what-goodleadership-looks-like-during-this-pandemic 
Kaminskiene \& Chu, 2021. Challenges of Distance Education During the School Lockdown: the Lithuanian School Leaders' Perspective

Lucas, N. \& Sims, D. (2020). Schools' Responses to Covid-19: Pupil Engagement in Remote Learning. NFER. Retrieved from: https://bit.ly/30IjCzL

SecEd. (2020). Covid safety measures will hit teaching standards, research warns. SecEd: The Voice for Secondary Education. Retrieved from: https://bit.ly/3ciG0DJ

Schueler, B. (2020). Summer "Vacation Academies" Can Narrow Coronavirus Learning Gaps. Education Next. Retrieved from: https://www.educationnext.org/summer-vacationacademies-narrow-coronavirus-learning-gaps-springfield/

Smith, L. \& Riley, D. (2012). School leadership in Times of Crisis. School Leadership \& Management, 32(1), 57-71.

Tang, T., Abuhmaid, A., Olaimat, M., Oudat, D., Aldhaeebie, M. \& Bamanger, E. (2020). Efficiency of flipped classroom with online-based teaching under COVID-19. Interactive Learning Environments.

UNICEF. (2020). Guidance: Assessing and Monitoring Learning During the Covid-19 Crisis. Verheijen, A. (2020) How to improve student engagement in online teaching during COVID19? FeedbackFruits: Driving Pedagogical Innovation. Retrieved from:https://feedbackfruits.com/blog/how-to-improve-student-engagement-in-onlineteaching-during-Covid-19

Zhan, T. (2020). Combat COVID-19: Keep learning. Together we are on the move! UNESCO Institute for Information Technologies in Education.

Zhao, Y. (2020). COVID-19 as a Catalyst for Educational Change. Prospects, pp. 1-5. 